\title{
Annual cycles and spring blooms in phytoplankton: don't abandon Sverdrup completely
}

\author{
Stephen M. Chiswell* \\ National Institute of Water \& Atmospheric Research (NIWA) Ltd, Private Bag 14-901, Kilbirnie, Wellington, New Zealand
}

\begin{abstract}
The critical-depth model for the onset of the spring phytoplankton bloom in the North Atlantic has recently been called into question by several researchers. The critical-depth model considers that the spring bloom starts when the mixed layer shoals to become shallower than a critical depth. Satellite and in situ measurements of chlorophyll are used here to show that the critical-depth model is indeed flawed. It is shown that the critical-depth model does not apply in the spring because the basic assumption of an upper layer that is well-mixed in plankton is not met. Instead, the spring bloom forms in shallow near-surface layers that deepen with the onset of thermal stratification. A stratification-onset model for the annual cycle in plankton is proposed that adheres to the conventional idea that the spring bloom represents a change from a deepmixed regime to a shallow light-driven regime, but where the upper layers are not well mixed in plankton in spring and so the critical-depth model does not apply. Ironically, perhaps, the criticaldepth model applies in the autumn and winter when plankton are well-mixed to the seasonal thermocline, so that the critical-depth model can be used to determine whether net winter production is positive or negative.
\end{abstract}

KEY WORDS: Phytoplankton $\cdot$ Spring bloom $\cdot$ Annual cycle $\cdot$ Remote sensing $\cdot$ Critical-depth model

Resale or republication not permitted without written consent of the publisher

\section{INTRODUCTION}

The classic critical-depth model for the onset of the spring phytoplankton bloom in the North Atlantic (e.g. Siegel et al. 2002) has recently been called into question by Behrenfeld (2010, hereafter B2010), Boss \& Behrenfeld (2010), and Taylor \& Ferrari (2011). The critical-depth model is based largely on the work of Sverdrup (1953) and Gran \& Braarud (1935), and considers that the spring bloom begins when the mixed layer shoals to become shallower than a critical depth where the vertically integrated production equals the vertically integrated losses.

B2010 used satellite measurements of ocean colour and numerical model estimates of mixed-layer depth to find that in the North Atlantic, vertically integrated carbon increases in winter even before the mixed layer reaches its deepest value. B2010 suggests that
'This finding strongly refutes the critical depth (model)' (p. 980). Instead, B2010 proposes a dilutionrecoupling model, where losses vary in time, and he notes 'herein lies the crucial flaw in the critical depth hypothesis: Sverdrup assumed (losses) to be constant over time'. B2010 invites 'other interpretations' of the data.

Productivity is relatively high in subtropical waters east of New Zealand (Fig. 1), and these waters also show a spring bloom that has been considered to be triggered by shoaling of the seasonal thermocline (Murphy et al. 2001). Here, similar methods to those described by B2010 are used to compute the annual cycles in surface chlorophyll a (hereafter, chlorophyll) and mixed-layer depth in the New Zealand region. These cycles, along with data from a spring bloom cruise made to the region, support a different interpretation for the breakdown of the critical-depth model than that suggested by B2010. 


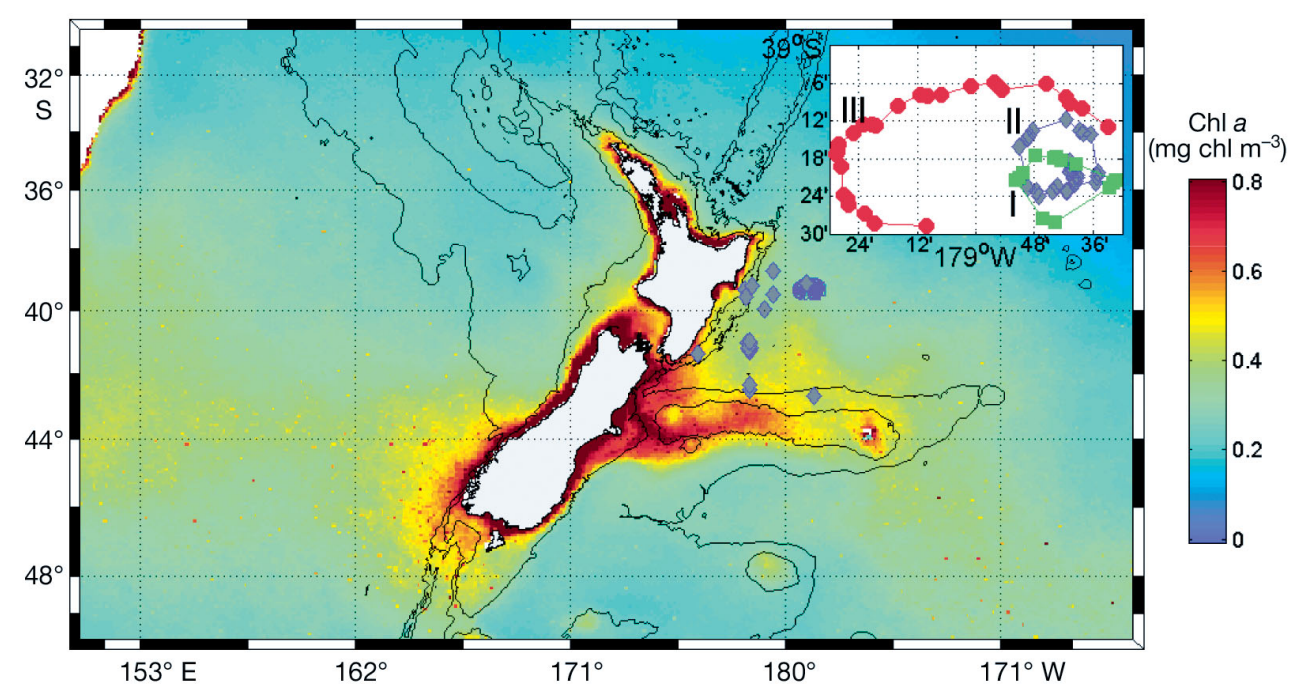

Fig. 1. Mean surface chlorophyll a $\left(\mathrm{mg} \mathrm{chl} \mathrm{m}^{-3}\right)$, derived from $13 \mathrm{yr}$ of SeaWiFS satellite observations of ocean colour. Blue diamonds show locations of CTD casts made during the 2008 spring bloom cruise; grey diamonds show locations of historical CTD casts (see 'Results, Historical CTD data'). Inset shows locations of CTD casts made during the 2008 spring bloom cruise. These casts were made tracking a drifter drogued at $15 \mathrm{~m}$ in order to follow an anticyclonic eddy. During the cruise, the eddy made 3 anticyclonic rotations, labelled I, II and III. Green, purple and red symbols, respectively, show CTD locations during these three rotations

The objective of this article is to present a conceptual model of the annual cycle in primary production in temperate waters where there is a spring bloom. In this 'stratification-onset' model, the annual cycle is controlled by the well-established mechanisms of deep mixing in the winter, and stratification in spring forming stable layers that allow near-surface production.

This article proceeds as follows. The next section discusses mixing and mixed-layer depths, and summarises the critical-depth model. The annual cycles in surface chlorophyll and mixed-layer depth off the east coast of New Zealand are then presented. This is followed by the results from the spring bloom cruise and available historical hydrographic data. The stratification-onset model is then presented. It is suggested that while the dilution and recoupling noted by B2010 occur, they are incidental to the annual carbon cycle, rather than define it.

Before continuing, however, it is important to make several comments. B2010 suggests that vertically integrated production may increase prior to the spring bloom, and states that 'bloom initiation occurs in the winter' (p. 977). Thus, there is room for possible confusion in the terminology related to the meaning of 'bloom'. In this article, the term 'spring bloom' is used to refer to the spring peak in surface chlorophyll, regardless of whether or not it indicates the beginning of the increase in total water-column plankton.
It appears that Sverdrup (1953) has been largely misinterpreted in the literature, and one has to distinguish carefully between the concept of a critical depth and the idea that the spring bloom is triggered when the surface mixed layer shoals to become shallower than this critical depth. Thus, in this article, the term 'Sverdrup (1953) hypothesis' is used to refer to the hypothesis that the critical depth is the level above which total production equals losses. The term 'critical-depth model' is used to refer to the idea that the spring bloom is triggered when the thermocline shoals above this critical depth.

The present study concentrates on chlorophyll, but it should be noted that chlorophyll can deviate from biomass because of physiological changes in intracellular pigmentation (Kruskopf \& Flynn 2006).

The mixed-layer depth is commonly defined to be the depth at which density exceeds the surface value by a specified difference, $\Delta \sigma$ (e.g. de Boyer Montégut et al. 2004). B2010 used a mixed-layer depth defined by $\Delta \sigma=0.125 \mathrm{~kg} \mathrm{~m}^{-3}$ (M. J. Behrenfeld pers. comm.). This depth, which is denoted as $Z_{0.125}$, is a good indicator of the depth of the seasonal thermocline.

\section{MIXING AND MIXED-LAYER DEPTHS}

It is important to recognise that apparently mixed (i.e. isopycnic) layers may not always be regions of rapid vertical mixing (e.g. Brainerd \& Gregg 1995). 
The mixed layer is, by definition, the upper layer of the ocean that is well mixed in temperature and salinity (and thus density). However, at any given time, this layer may not be a region of active mixing. For example, at the end of winter, there may be a remnant deep mixed layer that was formed by convective overturn and/or winter storms, but with the cessation of surface cooling and a reduction of windstress, vertical mixing within this upper layer is considerably reduced compared to the wintertime values.

If all horizontal processes are ignored, vertical mixing can be parameterised in terms of a vertical eddy diffusivity, $K(z, t)$, and the growth rate of chlorophyll, $C(z, t)$, at any level, $z$, and time, $t$, can be written (e.g. Huisman et al. 1999):

$$
\frac{\partial C}{\partial t}=C(\mu-1)+\frac{\partial}{\partial z} \frac{K \partial C}{\partial z}
$$

where $\mu(z, t)$ is the specific production rate (i.e. per unit chlorophyll), and $l(z, t)$ is the specific loss rate, which represents all losses including respiration, grazing, parasitism and sinking. In general, $K$ depends inversely on the stratification, because stronger stratification will damp out vertical mixing (e.g. Jassby \& Powell 1975).

The specific growth rate, $q$, in units $\left(\mathrm{d}^{-1}\right)$ at any level is given by:

$$
q(z, t)=\frac{\partial \ln (C)}{\partial t}
$$

where $q=\mu-1+\frac{1}{C} \frac{\partial}{\partial z} \frac{K \partial C}{\partial z}$.

Huisman \& Sommeijer (2002) and Taylor \& Ferrari (2011) argue that if $K$ is below a critical value, then vertical mixing may not be strong enough to mix plankton throughout the mixed layer, and there is the potential for plankton to remain sufficiently high in the water column so that blooms may develop regardless of the depth of the mixed layer. Such low rates of vertical mixing have been considered to account for observations of plankton blooms occurring even in the presence of deep mixed layers (Townsend et al. 1992). Conversely, when mixing is very fast compared to plankton growth rates then plankton are well mixed throughout the mixed layer.

It may be difficult in practice to determine from temperature and salinity profiles whether mixing is rapid or slow, but here it is argued that mixing generally results from surface terms - convective overturn and/or wind stress. Thus, if the mixed layer is deepening, active mixing extends to the base of the mixed layer. Hence, it is assumed that when the seasonal thermocline is deepening, all tracers including chlorophyll are well mixed to the seasonal thermocline (at least to a good approximation). However, when the seasonal thermocline is shoaling, one cannot make any statement about the strength of active mixing, and plankton may well be stratified in the mixed layer.

\section{Sverdrup (1953)}

Sverdrup (1953) assumed a nutrient-rich upper layer with strong mixing so that phytoplankton are homogenous throughout the upper layer. He assumed specific production $(\mu)$ to be proportional to light, specific losses (l) to be constant with depth, and that light, $I$, is attenuated with depth, such that:

$$
I(z)=I_{0} \exp \left(-k_{\mathrm{d}} z\right)
$$

where $I_{0}$ is the surface irradiance and $k_{\mathrm{d}}$ is the diffuse attenuation coefficient.

The critical-depth level $\left(Z_{\mathrm{cr}}\right)$ is defined to be the depth above which vertically integrated production equals the vertically integrated losses, so that:

$$
\int_{0}^{Z_{\text {cr }}} \mu_{0} \exp \left(-k_{\mathrm{d}} z\right) \mathrm{d} z=\int_{0}^{Z_{\mathrm{cr}}}\left(l_{0}\right) \mathrm{d} z
$$

where the subscript 0 indicates surface values.

Sverdrup (1953) defined the compensation irradiance to be the irradiance at the depth where 'photosynthesis balances destruction by respiration', although he used the term 'respiration' (p. 287) to mean all losses, including respiration, grazing and other losses such as sinking and parasitism. Because of his usage of the term respiration, there is the potential for confusion, and here the term 'equivalence irradiance', $I_{\mathrm{eq}}$, is introduced to mean the depth where production equals losses. The equivalence irradiance occurs at the equivalence depth, $Z_{\text {eq }}$.

With this substitution, the critical depth defined by Sverdrup (1953) is given by:

$$
\frac{1}{Z_{\text {cr }}}\left(1-\exp \left(-k_{\mathrm{d}} Z_{\mathrm{cr}}\right)\right)=k_{\mathrm{d}} \frac{I_{\text {eq }}}{I_{0}}
$$

If the mixed layer is shallower than $Z_{\text {cr }}$ there will be net positive growth in the mixed layer.

The assumption that losses are constant vertically was made to make the integrations in Eq. (4) mathematically tractable. If losses are depth dependent, then Eq. (4) can, in principle, be integrated numerically.

\section{The critical-depth model}

The critical-depth model stems from the Sverdrup (1953) hypothesis to suggest that, in the winter, the 
seasonal thermocline is deeper than the critical depth, so that net production is negative. The spring bloom is initiated when the seasonal thermocline shoals to become shallower than the critical depth.

It is worth emphasizing, that the critical depth $\left(Z_{\mathrm{cr}}\right)$ depends on $k_{\mathrm{d}}, I_{\mathrm{eq}}$, and $I_{0}$. All of these variables will change in time, so that the critical depth varies over the year. As light increases, the equivalence and critical depths deepen. As grazing increases (i.e. losses increase), the equivalence and critical depths shoal. However, time-varying critical depth does not change the concept in the critical-depth model that the bloom is triggered by shoaling of the mixed layer.

\section{METHODS}

Satellite data from the sea-viewing wide fieldof-view sensor (SeaWiFS) are available from the
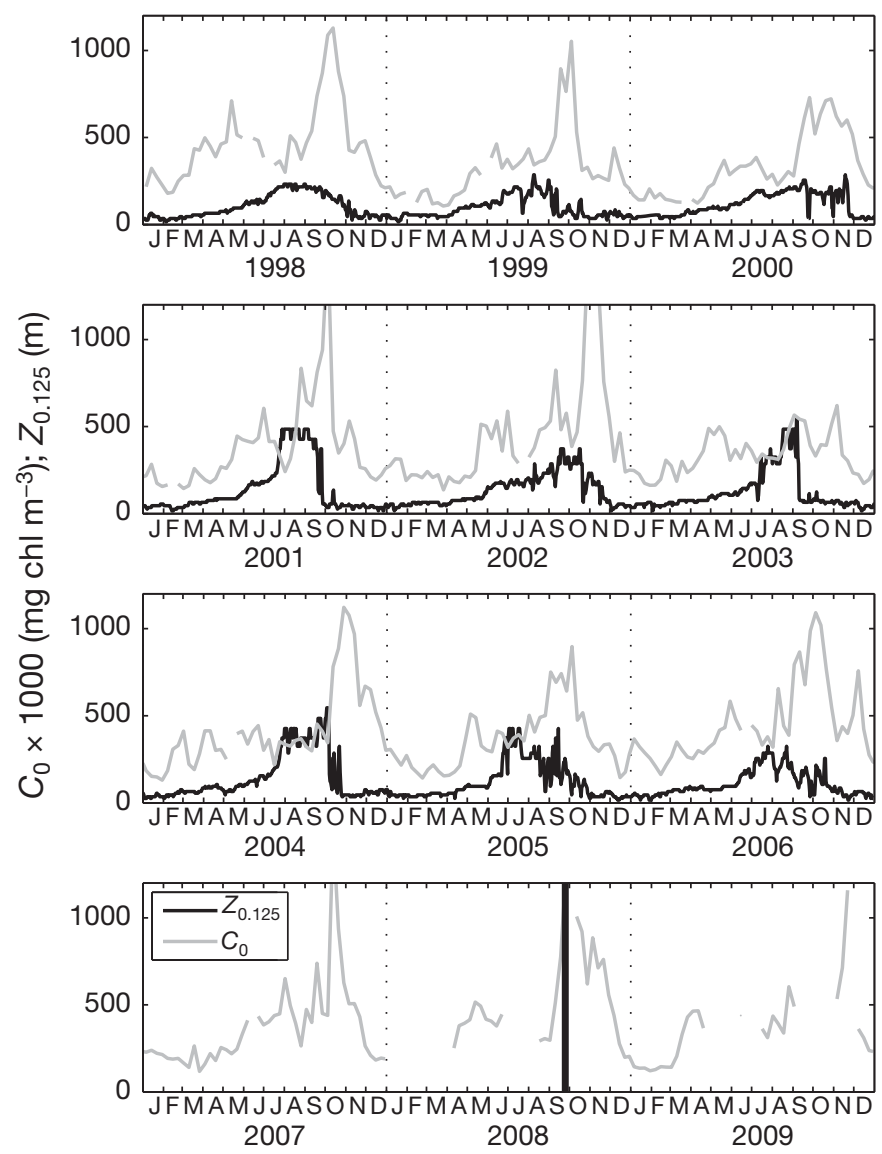

Fig. 2. Time series of satellite and numerical model products for the location of the 2008 spring bloom cruise $\left(39.3^{\circ} \mathrm{S}\right.$, $\left.178.9^{\circ} \mathrm{W}\right)$. Surface chlorophyll $\left(C_{0}\right)$ was derived from SeaWiFs data, and seasonal thermocline mixed-layer depth $\left(Z_{0.125}\right)$ was derived from a numerical model. Vertical line in 2008 indicates the start of the spring bloom cruise
NASA Ocean Color website (http://oceandata.sci. gsfc.nasa.gov/). Here, 8 d chlorophyll and photosynthetically available radiation (PAR) composite data mapped at a $9 \mathrm{~km}$ resolution from 1998 to 2010 were used. These $9 \mathrm{~km}$ data were further averaged into 36 by $36 \mathrm{~km}$ data using a median filter.

Meridional and zonal wind stress data were downloaded from the National Centers for Environmental Prediction (NCEP) Reanalysis Data (www.esrl. noaa.gov/psd/data/gridded/data.ncep.reanalysis. surfaceflux.html).

During the spring bloom cruise, conductivitytemperature-depth (CTD) measurements (e.g. Walkington \& Chiswell 1993) were made following an anticyclonic eddy off the east coast of New Zealand using a drifter drogued at $15 \mathrm{~m}$ to determine the eddy location (Fig. 1). Chlorophyll derived from the CTD fluorometer was calibrated against extracted chlorophyll from discrete water samples. Historical casts from the same region (Fig. 1) often had no calibration data, so nominal calibrations were applied.

Mixed-layer depths were calculated from CTDderived profiles of density for 2 values of $\Delta \sigma: 0.125$ and $0.025 \mathrm{~kg} \mathrm{~m}^{-3}$. These depths are denoted as $Z_{0.125}$ and $Z_{0.025}$, respectively. In the New Zealand region, the depths $Z_{0.125}$ and $Z_{0.025}$ correspond approximately to temperature differences of about 0.5 and $0.1^{\circ} \mathrm{C}$, respectively.

Numerical values of mixed-layer depth, $Z_{0.125}$, were computed from vertical temperature and salinity profiles derived from a 14 yr hindcast provided by the Bluelink project (Oke et al. 2005, 2008). This model is a $1 / 10^{\circ}$ resolution, 47 layer $z$-level primitive equation model.

\section{RESULTS}

\section{Satellite-derived annual cycles}

Mean surface chlorophyll (Fig. 1) illustrates a broad band running across the Tasman Sea and east of New Zealand at about 40 to $45^{\circ} \mathrm{S}$. This is associated with the Subtropical Front, which separates waters of subtropical origin (STW) from those of subantarctic origin (Chiswell 2001). The spring bloom cruise took place well north of this front in subtropical waters, characterised by surface salinity of $\sim 35.3$ to 35.5 and surface temperature of $\sim 20^{\circ} \mathrm{C}$ (summer) and $\sim 14^{\circ} \mathrm{C}$ (winter). Mean surface chlorophyll for the

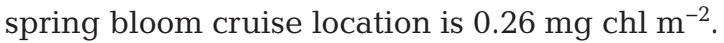

Time series of satellite-derived surface chlorophyll and numerical-model-derived mixed-layer depth 
$\left(Z_{0.125}\right)$ for the spring bloom cruise location are shown in Fig. 2. Both spring and autumn blooms occur in most years, although the amplitudes and timing vary considerably -2001 shows spring chlorophyll $>1 \mathrm{mg}$ chl m $\mathrm{m}^{-3}$, whereas 2003 shows little evidence of a spring bloom. The spring bloom peaks as early as 26 September (in 2000) and as late as 6 November (in 2002).

A simple mean broadens the average bloom compared to individual events; thus, Fig. 3 shows annual cycles computed after time-shifting the data in each year so that maximum chlorophyll values occur at the same time (this time was set to be the time of maximum of the simple mean). This procedure minimises smearing of the mean bloom, but retains the timing between chlorophyll and mixed-layer depth annual cycles. Annual cycles in wind stress and PAR are also shown.

The seasonal thermocline $\left(Z_{0.125}\right)$ is shallowest throughout summer, but then deepens through the
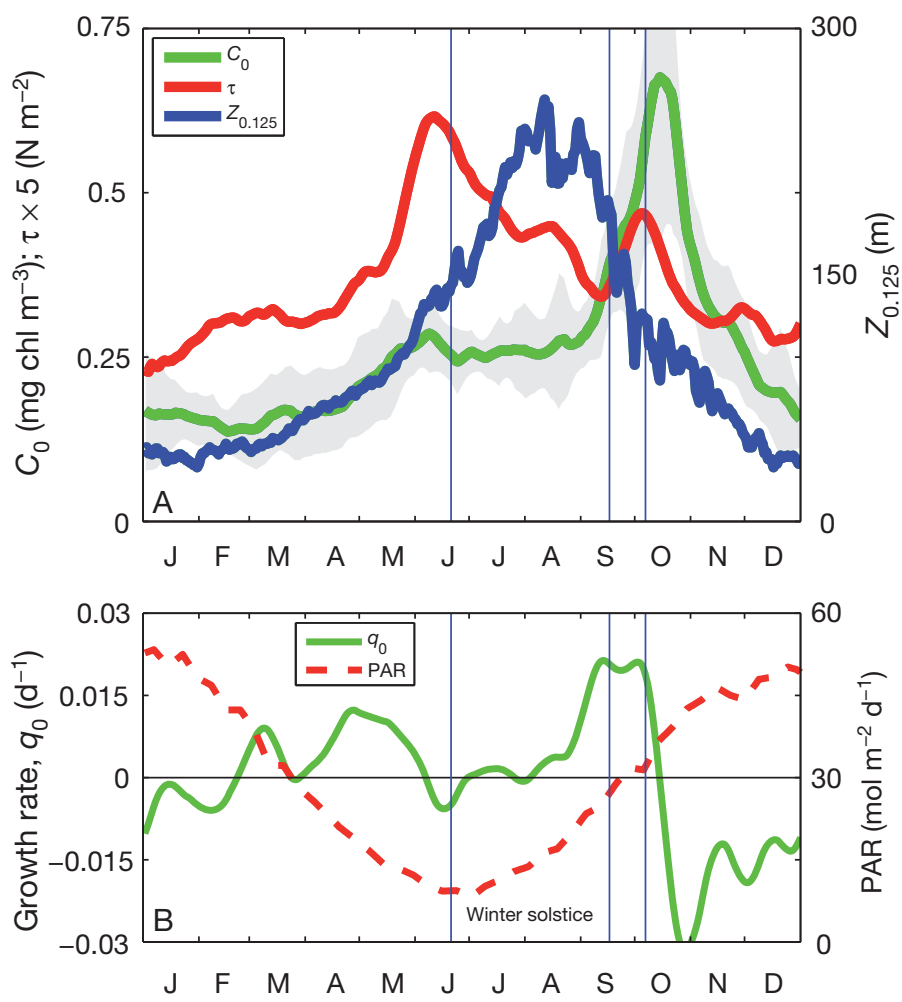

Fig. 3. (A) Annual cycles in surface chlorophyll $\left(C_{0}\right)$, mixedlayer depth $\left(Z_{0.125}\right)$ derived from the numerical model, and wind stress $(\tau)$ for the mean location of the 2008 spring bloom cruise $\left(39.3^{\circ} \mathrm{S}, 178.9^{\circ} \mathrm{W}\right)$. Grey shading indicates 1 standard deviation for $C_{0}$. (B) Annual cycle in the specific surface chlorophyll growth rate. Vertical bar in June indicates the winter solstice; vertical bars in September and October indicate the start and end of the 2008 spring bloom cruise autumn and winter so that the deepest mixed layers occur in August. After this, the thermocline shoals to reach summer values by mid-December. Independent evaluation of the thermocline depth from Bluelink (not shown here) indicates that the model may be overestimating the depth, but the timing is correct. Annual wind stress peaks in June, just prior to the winter solstice, but then generally decreases through winter and into summer, although there is a second peak near the spring equinox. PAR is locked to the solar cycle.

Starting from low surface chlorophyll conditions in summer, there is a late autumn/early winter bloom (May/June) which peaks at about $0.26 \mathrm{mg} \mathrm{chl} \mathrm{m}^{-3}$. This is followed by nearly constant chlorophyll during winter (July/August). The spring bloom lasts from late September to early November, with maxi-

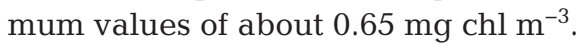

The standard deviation of the annual cycle in surface chlorophyll is large enough that the autumn peak is not significant. However, an inspection of the time series (Fig. 2) indicates that in almost every year (except 2003), there are autumn peaks in chlorophyll, but these peaks have such large variability in timing that they tend to average out in the mean.

The specific growth rate, $q_{0}$, of surface chlorophyll

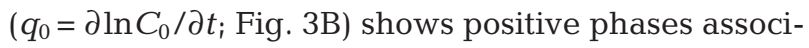
ated with the autumn and spring blooms, with nearzero values in winter. The spring phase starts just after the seasonal thermocline reaches its maximum depth. Maximum spring growth rates of about $0.02 \mathrm{~d}^{-1}$ are ca. $20 \%$ higher than those for the autumn bloom.

\section{Spring bloom cruise 2008}

The cruise took place near the onset of the spring bloom in 2008 (Fig. 2). CTD casts were made at nominal $6 \mathrm{~h}$ intervals over $18 \mathrm{~d}$ following a drifter (Fig. 1). This drifter was initially deployed near the centre of an anticyclonic eddy that had previously been identified from satellite measurements of seasurface height. The eddy made 3 rotations during the cruise, labelled I to III. Rotations I and II had radii of about $10 \mathrm{~km}$; however, during rotation III, the winds rose (Fig. 4), and the radius of rotation increased dramatically, suggesting that that the buoy left the centre of the eddy during this time.

Temperature and chlorophyll from the CTD casts are shown in Fig. 4. Fluorescence quenching during the day has been filtered out of the plot by including only data taken between 22:00 and 08:00 h local time. 
For most of the experiment $Z_{0.125}$ was about 300 to $400 \mathrm{~m}$ deep -i.e. there was $<0.5^{\circ} \mathrm{C}$ temperature difference in the top $300 \mathrm{~m}$, showing the presence of deep, nearly isothermal remnant winter mixed layers. However, during the calm period starting 22 September, heating of the upper water column led to a surface temperature rise of about $0.4^{\circ} \mathrm{C}$ over $3 \mathrm{~d}$. This heating initially penetrated about $10 \mathrm{~m}$, but as the winds rose after 25 September, it was mixed down to about $50 \mathrm{~m}$. Stronger winds later mixed this
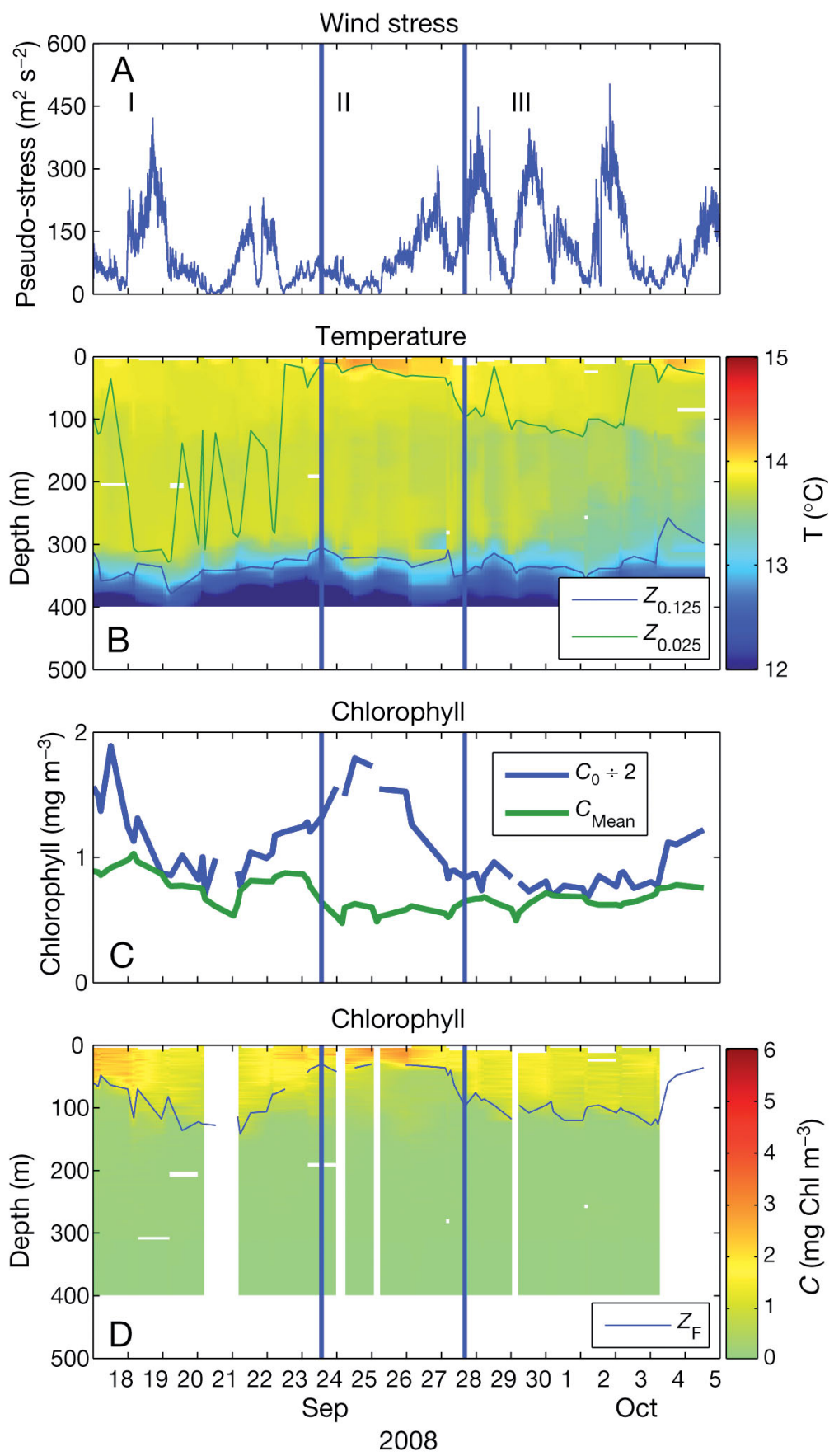

heat down further. During Rotation III, waters at from 200 to $300 \mathrm{~m}$ depth show some warming, probably associated with the drifter (and hence CTD sampling) exiting the core of the eddy.

Surface chlorophyll was high at the beginning of the survey, decreased, and then rose to a local maximum on 25 September just before the winds increased during Rotation II. However, the mean chlorophyll over the top $200 \mathrm{~m}$ (i.e. vertically averaged chlorophyll) was remarkably constant. The depth of the chlorophyll layer, $Z_{\mathrm{F}}$, calculated from the maximum vertical gradient in chlorophyll, was comparable to $Z_{0.025}$ over much of the experiment, thus illustrating that surface chlorophyll was contained in density layers that correspond to temperature differences of $0.1^{\circ} \mathrm{C}$ or less. The spring bloom was limited to the upper $150 \mathrm{~m}$, even in the presence of deep remnant mixed layers.

The main conclusions derived from Fig. 4 (i.e. that the spring bloom is limited to the upper layers) can also be illustrated through vertical profiles of temperature and chlorophyll made near midnight on 4 successive nights from 24 to 28 September during Rotation II (Fig. 5). All 4 casts show shallow surface layers overlying deep remnant mixed layers extending to nearly $300 \mathrm{~m}$. Chlorophyll is surface intensified and not homogeneous in the deep remnant mixed layers. During this period of time, increasing winds led to deepening of the near-surface layers (deepening $Z_{0.025}$ from 11 to $33 \mathrm{~m}$ ), while the thermocline shoaled slightly $\left(Z_{0.125}\right.$ shoaled from 313 to $304 \mathrm{~m}$ ).

Fig. 4. Observations made during the 2008 spring bloom cruise. Blue vertical bars indicate the 3 rotations of the anticyclonic eddy tracked during the cruise, labelled I, II and III (see 'Results, Spring bloom cruise 2008'). (A) Pseudo-wind stress from shipboard observations. (B) Temperature section. Two estimates of mixed-layer depth $\left(Z_{0.125}\right.$ and $\left.Z_{0.025}\right)$ derived from the CTD data are shown, as discussed in 'Results, Spring bloom cruise 2008'. (C) Surface $\left(C_{0}\right)$ and mean chlorophyll $(C)$ derived from a CTD fluorometer over the upper $200 \mathrm{~m}$ - surface chlorophyll has been divided by 2 . (D) Chlorophyll section derived from fluorescence. The base of the chlorophyll layer, $Z_{\mathrm{F}}$, defined as the region of maximum vertical gradient, is shown 

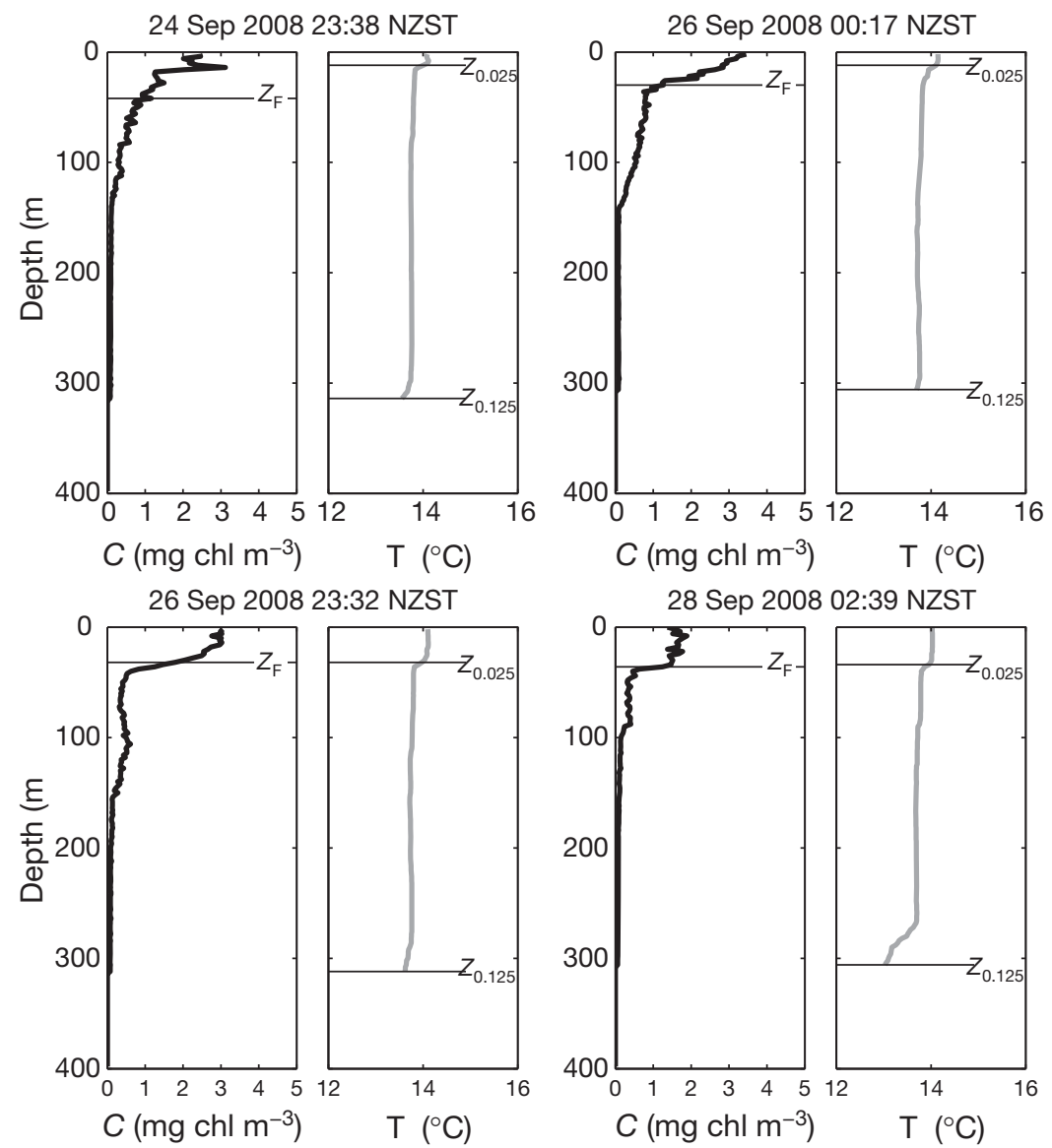

Fig. 5. Temperature (T) and chlorophyll $(C)$ profiles from CTD casts made approximately $24 \mathrm{~h}$ apart during the spring bloom cruise (locations are shown in Fig. 1). Two estimates of mixed-layer depth $\left(Z_{0.125}\right.$ and $\left.Z_{0.025}\right)$ derived from the CTD data are shown. $Z_{\mathrm{F}}$ : base of chlorophyll layer

2008 spring bloom cruise results, showing deep remnant winter layers and shallow surface stratification (i.e. deep $Z_{0.125}$ but shallow $Z_{0.025}$, with chlorophyll trapped in the surface layers.

\section{THE STRATIFICATION-ONSET MODEL}

The observations that the spring bloom does not start until after the deepest mixing (Fig. 3), that it starts in the surface layers, and that it is not well mixed to the seasonal thermocline (Figs. 4 to 6 ) lead to a model for the seasonal cycle in plankton that incorporates conventional mechanisms of nutrient and light availability combined with mixing in the surface mixed layer.

The basic tenets of the stratification-onset model are that the seasonal thermocline is at its shallowest in summer because of high summer solar insolation and relatively light wind stress. Nutrients are depleted in summer (e.g. Nodder et al. 2005) so that production depends on the vertical flux of nutrients through the thermocline and chlorophyll shows a subsurface maximum near the thermocline. During autumn and winter, increased windstress, combined with surface cooling and convective overturn, increase surface-driven mixing, and this mixing

\section{Historical CTD data}

Twenty-eight historical temperature and chlorophyll profiles from the region (Fig. 1) can be used to illustrate the annual cycle (Fig. 6). Generally, summer profiles (December to February) show subsurface chlorophyll peaking at the shallow seasonal thermocline, although 1 cast (31 December 1999) suggests that, even in summer, storms can lead to deep mixing. Autumn profiles (March to May) show a progression of deepening thermocline and increased mixing of the upper layers so that chlorophyll profiles progressively become more vertically mixed. Winter profiles (July to August) tend to show deep $(\sim 300 \mathrm{~m})$ isothermal layers and wellmixed chlorophyll. However, even in winter, there can be some thermal stratification and gradients in the chlorophyll (8 July 2006). Spring (September to October) profiles generally are consistent with the deepens the seasonal thermocline. Initially, this mixing leads to increased production in response to entrainment of nutrients. The deepening thermocline implies that vertical mixing is rapid enough that all tracers including chlorophyll are well mixed (to a good approximation) above the thermocline. Thus, if the winter thermocline deepens below the critical depth, net production will become negative. During the spring, however, windstress generally decreases and convective overturn shuts down, so that deep mixing ceases. The seasonal thermocline represents the base of the deep remnant mixed layer, but does not represent the depth of vertical mixing. Instead, shallow, weak (i.e. $\Delta \sigma \approx 0.025 \mathrm{~kg} \mathrm{~m}^{-3}$ ), surface mixed layers may emerge soon after the thermocline reaches its maximum depth. The spring bloom initiates near the surface in these layers, even if the thermocline is deeper than the critical depth. Production in these surface layers will be positive, since they are 

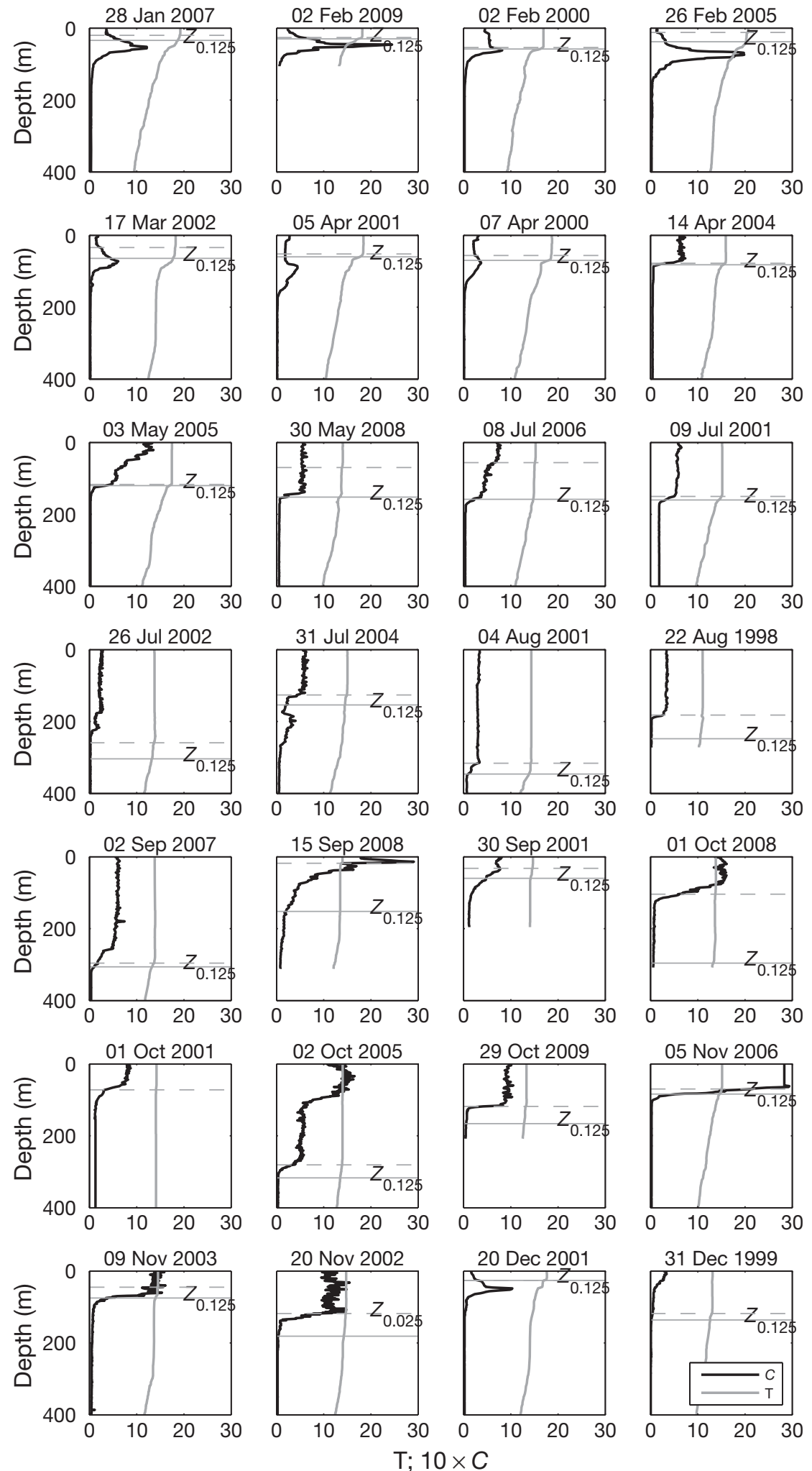

Fig. 6. Temperature and chlorophyll profiles from the historic CTD casts (locations are shown in Fig. 1). Chlorophyll has been scaled by 10. The profiles show 2 estimates of mixed-layer depth, $Z_{0.125}$ (horizontal lines) and $Z_{0.025}$ (horizontal dashed lines) derived from the CTD data. The profiles are plotted according to the calendar day almost certainly shallower than the critical depth. In the deep remnant mixed layer below these surface mixed layers, production will exceed losses above the equivalence depth. This production will be mixed vertically by (weak) mixing, and chlorophyll will show quasi-exponential decrease with depth. Grazing increases rapidly after the initiation of the spring bloom, and this, together with consumption of nutrients, leads to a return to summer-time conditions.

Fig. 7 shows a schematic for this stratification-onset model for 2 hypothetical oceans. These oceans are similar, except that Ocean 1 represents an ocean where vertically integrated production exceeds losses throughout winter. Ocean 2 represents an ocean which enters a lossdominated phase in winter that could be due to either (or both) light limitation or high grazing. Under B2010's definition, Ocean 1 is decoupled all winter, whereas Ocean 2 becomes coupled in winter.

The thermocline depth shown in the figure is based on $Z_{0.125}$ for the spring bloom cruise location, i.e. its timing is realistic for the New Zealand region. The figure also shows the equivalence and critical depths, $Z_{\text {eq }}$ and $Z_{\text {cr }}$ for both hypothetical oceans. These values were calculated assuming a diffuse attenuation coefficient, $k_{\mathrm{d}}$, equivalent to a $1 \%$ light level of $50 \mathrm{~m}$. The equivalence irradiance, $I_{\text {eq, }}$ was set to $0.6 \mathrm{~mol} \mathrm{~m}^{-2} \mathrm{~d}^{-1}$ for Ocean 1 and to $1.2 \mathrm{~mol} \mathrm{~m}^{-2} \mathrm{~d}^{-1}$ for Ocean 2. These values are in the range of observed values (e.g. Siegel et al. 2002). Because of the exponential nature of light extinction, there is only a difference of about $5 \mathrm{~m}$ between the equivalence depths for the 2 oceans, but the critical depth for Ocean 1 is $>100 \mathrm{~m}$ deeper than that for Ocean 2 (Fig. 7A).

The middle panel of Fig. 7 illustrates the growth of the watercolumn-integrated chlorophyll, $r=$ $\partial C_{\text {tot }} / \partial t$, for the 2 oceans, where 
$C_{\text {tot }}=\int_{0}^{H} C \mathrm{~d} z$, and $H$ is the water depth. The actual values of $r$ are arbitrary - it is the relative magnitude and sign in these values that differentiate Ocean 1 from Ocean 2. The lower panel of Fig. 7 illustrates the total chlorophyll, $C_{\text {tot, }}$ derived by integrating $r$ from an initial value of 100 units.

Both oceans start summer with a subsurface maximum in chlorophyll, and the growth rates, $r$, are negative because losses dominate production.
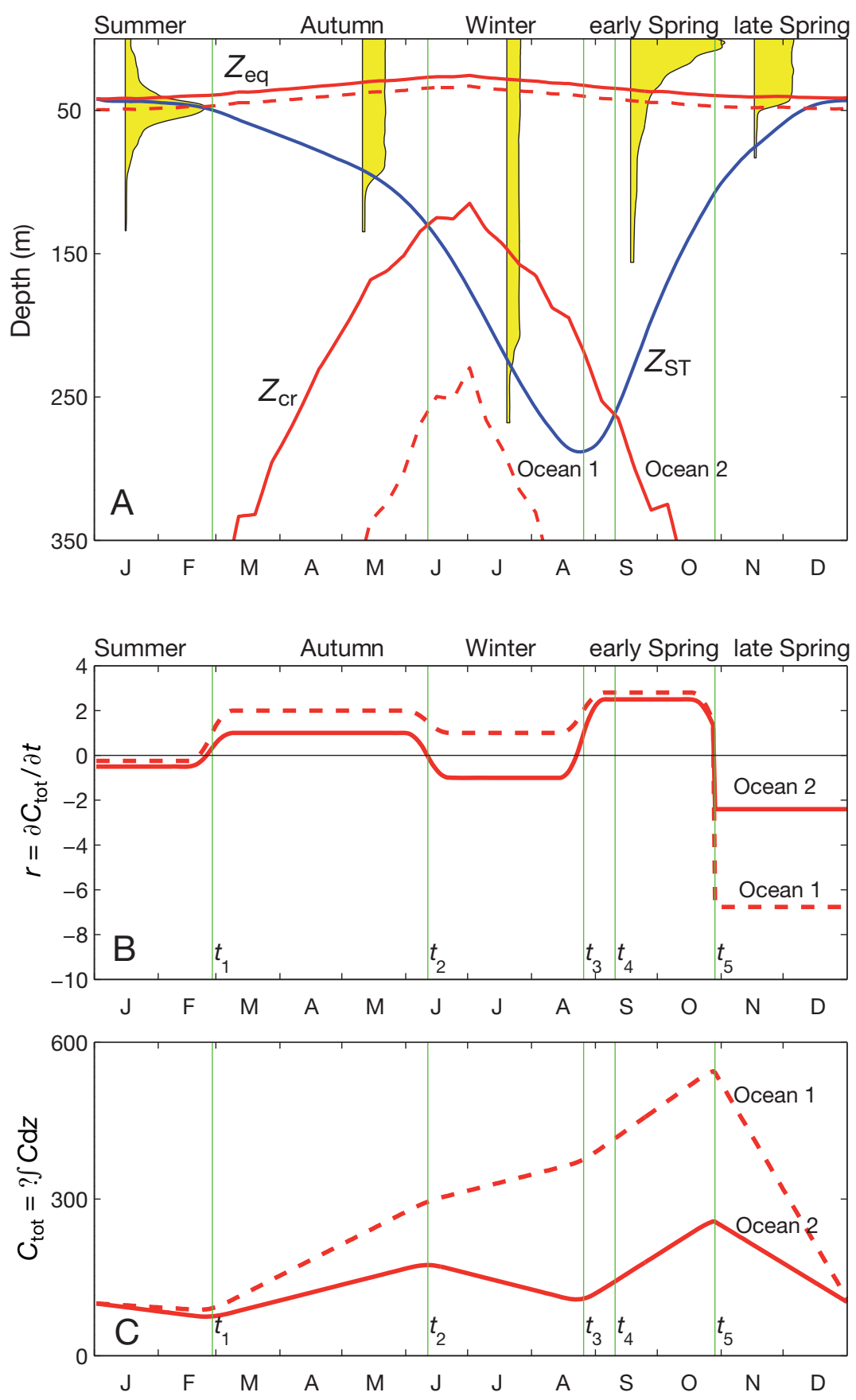

The seasonal thermocline starts to deepen in early autumn due to increased mixing, this time is denoted $t_{1}$ in Fig. 7. Deepening of the thermocline continues through the winter until the seasonal thermocline reaches its maximum depth at time $t_{3}$ (Fig. 7). While the thermocline is deepening, all tracers are well mixed to the thermocline depth. However, the 2 hypothetical oceans behave quite differently during this time. For Ocean 1, the thermocline never deepens below its critical depth. Thus, for this uncoupled ocean, net production is positive throughout autumn and winter, provided there are sufficient nutrients (although it is still possible that surface chlorophyll decreases due to dilution as discussed by B2010). For Ocean 2, however, the thermocline becomes deeper than its critical depth at time $t_{2}$, and thus, for this ocean, net production is negative between $t_{2}$ and $t_{3}$ (Fig. 7B).

Once the thermocline ceases to deepen at time $t_{3}$, emerging stratification in the surface layers and weak mixing there can support a spring bloom for both oceans. The spring water column is characterised by shallow weak mixed layers lying over a remnant winter

Fig. 7. Schematic of the annual cycle in primary production. (A) Depth of the seasonal thermocline, $Z_{\mathrm{ST}}$ (blue line), and equivalence and critical depths, $Z_{\text {eq }}$ and $Z_{\text {cr }}$ for 2 hypothetical oceans (red lines). Ocean 1 (dashed lines) is one where production exceeds losses in winter, and Ocean 2 (solid line) is one where losses exceed production in winter. In summer, chlorophyll (yellow profiles) shows a sub-surface maximum at $Z_{\mathrm{ST}}$. During autumn and winter, chlorophyll is mixed through the mixed layer. If the thermocline is shallower than the critical depth $\left(Z_{\mathrm{cr}}\right)$ net production can be positive given sufficient nutrients. In spring, the thermocline shoals due to erosion at the base of the mixed layer. The spring chlorophyll bloom starts at the surface when deep mixing ceases, allowing intermittent surface mixed layers to appear. By summer, grazing and nutrient depletion reduce chlorophyll in the upper layers. (B) Growth rates of vertically integrated production for Ocean 1 and Ocean 2, see 'The stratificationonset model'. (C) Vertically integrated biomass for Oceans 1 and 2, derived by integrating the growth rates shown in Fig. $7 \mathrm{~B}_{;} t_{1}$ to $t_{5}$ indicate various times in the annual cycle as discussed in the section 'The stratificationonset model' 
mixed layer for both oceans. Eventually the thermocline shoals to summer values and grazing and nutrient depletion lead to reduced chlorophyll as summer conditions return.

The vertically integrated chlorophyll (Fig. 7C) shows different annual cycles for the 2 hypothetical oceans. The uncoupled Ocean 1 shows increasing chlorophyll from autumn to spring, whereas the coupled Ocean 2 shows distinct autumn and spring peaks in vertically integrated chlorophyll. Averaged over the year, net production must equal net losses for both oceans, and this manifests itself in much higher losses in Ocean 1 during the late spring.

\section{DISCUSSION}

The stratification-onset model presented here adheres to the conventional idea that the initiation of the spring bloom represents a change from a deepmixed regime to a shallow light-driven regime, but with the important realisation that stratification of plankton can be significant within the classically defined mixed layer.

It is an often overlooked fact that the depth of the seasonal thermocline is not, in general, a measure of the depth of vertical mixing of plankton. Instead, the vertical mixing of plankton is controlled by processes that can be parameterised in terms of vertical eddy diffusivity, so that the distribution of plankton is determined by a solution to Eq. (1). In the limit of high vertical mixing, plankton will be uniformly mixed to the base of the mixed layer, and net growth depends on whether the mixed layer is shallower or not than the critical depth. In the other limit of low vertical mixing, net growth will be positive only above the equivalence depth. For intermediary values of mixing, there can be net growth to some depth below the equivalence depth because of a downwards flux of plankton.

B2010 suggests that in the North Atlantic, the deepening thermocline in winter dilutes both plankton and grazers. This dilution leads to low losses (i.e. low coupling) in winter, with the result that watercolumn-integrated production can become positive, i.e. the North Atlantic behaves like Ocean 1 in Fig. 7. There are not enough data to determine with certainty whether subtropical water off the east coast of New Zealand is uncoupled in mid-winter or not. Fig. 3 indicates that surface chlorophyll is approximately constant in winter when the thermocline is deepening, indicating total biomass is increasing and that the ocean is uncoupled. However, the error bars on the mean surface chlorophyll are large enough that this result is uncertain. Evidence suggests that grazing by microzooplanton is higher in winter than in spring (James \& Hall 1998), and it may be that in some years the winter ends in a coupled state.

It is beyond the scope of this article to determine if any real ocean behaves like Ocean 2 in Fig. 7 , but it should be stressed that the stratification-onset model, makes no a priori statement about winter-time production-total water-column biomass can either decrease or increase in winter. The stratificationonset model requires increasing losses (i.e. increasing coupling) only to explain the demise of the spring bloom. It is relatively well established that both grazing and nutrient depletion contribute to the end of the bloom (e.g. Nodder et al. 2005). However, any transition from a decoupled to a coupled state is incidental to, rather than necessary for initiation of the spring bloom.

In a paper published at about the same time as this one, Taylor \& Ferrari (2011) propose a mechanism for the initiation of the spring bloom that is very similar to that proposed here. They suggest that the onset of the spring bloom in the North Atlantic is triggered by the reduction in air-sea fluxes at the end of winter, which leads to lowered vertical mixing near the surface and thus allows the establishment of the spring bloom. Their conclusion that the spring bloom should coincide with the end of convective overturn is, for most practical purposes, the same as the conclusions made here, because the development of near-surface stratification requires both the shutdown of convective overturn and low windstress.

Thus, the mechanisms of the stratification-onset model are expected to be typical in temperate waters showing a spring bloom, and this includes the North Atlantic, although details of the annual cycle (such as whether the real ocean behaves more like Ocean 1 or Ocean 2) will be regionally specific.

The critical-depth model has been used extensively in the literature, where the mixed-layer depth is taken to be the depth of the thermocline (e.g. Dutkiewicz et al. 2001, Siegel et al. 2002). It could be suggested that the critical-depth model has simply been misused, and that one should use a mixed-layer depth appropriate to the developing bloom - i.e. one might use $Z_{0.025}$ instead of $Z_{0.125}$. But this would be a false interpretation, because the assumptions made by Sverdrup (1953) leading to the concept of a critical depth do not apply in the spring. Ironically, perhaps, the assumptions underlying the critical-depth model apply in autumn and winter, when the deepening thermocline may turn off production. 
It should be noted that the stratification-onset model is a model of the average annual cycle. The model assumes that on average the seasonal thermocline deepens throughout autumn and winter. In any given year, this deepening will not be monotonic, and there may be periods when vertical mixing is weak (for example between storms). Thus, there may be intermittent periods where near-surface blooms occur during winter even in the presence of deep surface mixed layers. Observations of such blooms in deep mixed layers led Huisman et al. (1999) to model the ocean according to Eq. (1) and show that a bloom can occur 'irrespective of the thickness of the upper water column' (p. 1781), when vertical mixing is weak enough. This idea was recognised by Townsend et al. (1994, p. 748) who tried to 'dispel the pervasive notion that a deep mixed layer implies that phytoplankton are continually being mixed to great depths'. Such winter blooms are, in principle, little different from spring blooms, except that they will be deeply mixed down in the next convective overturn event.

Like all conceptual models, the stratification-onset model is highly simplistic and does little more than provide a framework to describe the annul cycle in primary production. It has been assumed that the system is 1-dimensional so that horizontal processes are not important. In reality, horizontal processes may be very important in the redistribution of nutrients and/or buoyancy, and it has been suggested that mesoscale eddies may be important in controlling the timing and magnitude of the spring bloom (Levy et al. 2000). In addition, the shoaling of the thermocline in spring (i.e. restratification) has been suggested to be controlled through 3-dimensional processes by slumping of lateral density gradients resulting from spatial variations in the winter mixed layers (Boccaletti et al. 2007).

Finally, the idea that the spring bloom initiates at the surface is not particularly new. Indeed, Sverdrup (1953) himself discusses his result in terms of the development of a shallow mixed layer. Smetacek \& Passow (1990) comment that the spring bloom is governed by processes occurring close to the surface. It is thus a little surprising that the critical-depth model apparently remains so entrenched that B2010 felt the need to 'abandon' it. It is time that the criticaldepth model of the spring bloom be reconsidered.

Acknowledgements. SeaWiFs data were made available by the Ocean Color Group. NCEP Reanalysis data were provided by the NOAA/OAR/ESRL PSD, Boulder, Colorado, USA, from their web site at www.cdc.noaa.gov/psd. Bluelink numerical model data were provided by D. Griffin and P. Oke of CSIRO, Australia. I thank all those involved in data collection during the cruise, including the Master and crew of RV 'Tangaroa'. I thank P. Boyd and S. Nodder for kindly allowing me to publish the spring bloom cruise and historical CTD data from biophysical moorings cruises. J. Bradford-Grieve, P. Calil, G. Rickard, P. Sutton and S. Kennan are thanked for insightful discussion. The comments from reviewers, including R. Ferrari and M. Behrenfeld, greatly improved this paper. This work was funded by the Foundation of Research Science and Technology (NZ) under the Coasts and Oceans Outcome-Based Investment (C01X0501) and Climate Variability \& Change Programme (C01X0701).

\section{LITERATURE CITED}

Behrenfeld MJ (2010) Abandoning Sverdrup's critical depth hypothesis on phytoplankton blooms. Ecology 91: 977-989

Boccaletti G, Ferrari R, Fox-Kemper B (2007) Mixed layer instabilities and restratification. J Phys Oceanogr 37: 2228-2249

Boss E, Behrenfeld M (2010) In situ evaluation of the initiation of the North Atlantic phytoplankton bloom. Geophys Res Lett 37:L18603 doi:10.1029/2010GL044174

Brainerd KE, Gregg MC (1995) Surface mixed and mixing layer depths. Deep-Sea Res I 42:1521-1543

> Chiswell SM (2001) Eddy energetics in the Subtropical Front over the Chatham Rise. N Z J Mar Freshw Res 35:1-15

- de Boyer Montégut C, Madec G, Fischer AS, Lazar A, Iudicone D (2004) Mixed layer depth over the global ocean: an examination of profile data and a profile-based climatology. J Geophys Res 109:C12003, doi:10.1029/ 2004JC002378

> Dutkiewicz S, Follows M, Marshall J, Gregg WW (2001) Interannual variability of phytoplankton abundances in the North Atlantic. Deep-Sea Res II 48:2323-2344

Gran HH, Braarud T (1935) A quantitative study on the phytoplankton of the Bay of Fundy and the Gulf of Maine (including observations on hydrography, chemistry and morbidity). J Biol Board Can 1:219-467

Huisman J, Sommeijer B (2002) Maximal sustainable sinking velocity of phytoplankton species. Mar Ecol Prog Ser 244:39-48

> Huisman J, van Oostveen P, Weissing FJ (1999) Critical depth and critical turbulence: two different mechanisms for the development of phytoplankton blooms. Limnol Oceanogr 44:1781-1878

James MR, Hall JA (1998) Microzooplankton grazing in different water masses associated with the subtropical convergence round the south island, New Zealand. Deep-Sea Res I 45:1689-1707

> Jassby AJ, Powell T (1975) Vertical patterns of eddy diffusion during stratification in Castle Lake, California. Limnol Oceanogr 20:530-543

Kruskopf M, Flynn KJ (2006) Chlorophyll content and fluorescence responses cannot be used to gauge reliably phytoplankton biomass, nutrient status or growth rate. New Phytol 169:525-536

> Levy M, Memery L, Madec G (2000) Combined effects of mesoscale processes and atmospheric high-frequency variability on the spring bloom in the MEDOC area. Deep-Sea Res I 47:27-53

Murphy RJ, Pinkerton MH, Richardson KM, BradfordGrieve JM, Boyd PW (2001) Phytoplankton distributions 
around New Zealand derived from SeaWiFS remotelysensed ocean colour data. N Z J Mar Freshw Res 35: 343-362

Nodder SD, Boyd PW, Chiswell SM, Pinkerton M, Greig M (2005) Temporal coupling between surface and deepocean biophysical and biogeochemical processes in contrasting subtropical and subantarctic waters, east of New Zealand. J Geophys Res 110:C12017, doi:10.1029/ 2004JC002833

Oke PR, Schiller A, Griffin DA, Brassington GB (2005) Ensemble data assimilation for an eddy-resolving ocean model of the Australian region. Q J R Meterol Soc 131: 3301-3311

Oke PR, Brassington GB, Griffin DA, Schiller A (2008) The Bluelink Ocean Data Assimilation System (BODAS). Ocean Model 21:46-70

Siegel DA, Doney SC, Yoder JA (2002) The North Atlantic spring phytoplankton bloom and Sverdrup's critical depth hypothesis. Science 296:730-733

Editorial responsibility: Antonio Bode, A Coruña, Spain,
Smetacek V, Passow U (1990) Spring bloom initiation and Sverdrup's critical-depth model. Limnol Oceanogr 35: 228-234

Sverdrup H (1953) On conditions for the vernal blooming of phytoplankton. J Cons Cons Int Explor Mer 18:287-295

Taylor JR, Ferrari R (2011) Shutdown of turbulent convection as a new criterion for the onset of spring phytoplankton blooms. Limnol Oceanogr 56:2293-2307

Townsend DW, Keller MM, Sieracki ME, Ackleson SG (1992) Spring blooms in the absence of vertical water column stratification. Nature 360:59-62

Townsend DW, Cammen LM, Holligan PM, Campbell DE, Pettigrew NR (1994) Causes and consequences of variability in the timing of spring phytoplankton blooms. Deep-Sea Res I 41:747-765

Walkington CM, Chiswell SM (1993) CTD observations in the subtropical convergence Chatham Rise. Physics Section Report 93/1. Physics Section, New Zealand Oceanographic Institute, Wellington

Submitted: July 22, 2011; Accepted: October 16, 2011

Proofs received from author(s): December 8, 2011 